\title{
Dauthendey, Dörmann, Stramm: três poetas, três poemas
}

Augusto Rodrigues

Neste artigo será apresentada a tentativa de tradução de três poemas eróticos, cada um de um poeta de língua alemã do início do século XX, autores que são relativamente desconhecidos no Brasil e praticamente esquecidos na Alemanha, mesmo a despeito de sua representatividade dentro dos movimentos literários a que pertenceram.

Comecemos com o romancista, dramaturgo, poeta e pintor Max Dauthendey (1867-1918), que, segundo Walter Benjamin ${ }^{1}$ na resenha de uma edição de suas cartas, se auto-apresenta em 1897 da seguinte forma: "Ich bin deutscher Schriftsteller und habe in Europa in Petersburg, Berlin, München, London, Stockholm, Paris, Venedig und Sizilien Literatur, Malerei und Musik studiert", o que equivaleria em português a: "Sou escritor alemão e estudei literatura, pintura e música na Europa em São Petersburgo, Berlim, Munique, Londres, Estocolmo, Paris, Veneza e Sicília". Sua lírica e prosa rítmicas, marcadas por uma riqueza de cores e tons fizeram de Dauthendey um dos principais representantes do impressionismo na Alemanha. Entre suas obras líricas se encontram: Die ezwige Hochzeit

BENJAMIN, Walter. “Briefe von Max Dauthendey". In: Gesammelte Schriften. Frankfurt: Suhrkamp, 1997. 
("O casamento eterno", 1905), Singsangbuch ("Livro de cantigas", 1907) e Weltspuk ("Assombração do mundo", 1910), salvo engano, nenhuma delas traduzida no Brasil. ${ }^{2}$.

O poema selecionado para tradução pertence à coletânea de canções de amor Die ewige Hochzeit:

\section{Nie war die eine Liebesnacht..}

Nie war die eine Liebesnacht

In deinem Schoss der andern gleich,

Dein Leib ist ein Septembermond

An immer neuen Früchten reich.

Die Brüste sind ein Traubenpaar,

Und drinnen pocht der junge Wein,

Die Augen sind ein Himmelstor

Und lassen meine Wünsche ein.

\footnotetext{
No site da Revista Zunái (http://www.revistazunai.com.br/traducoes/ max_dauthendey.htm) André Vallias apresenta a tradução de quatro poemas da primeira coletânea de Dauthendey, intitulada Ultra Violett (1893), juntamente com uma breve biografia do poeta.
} 


\section{No teu colo, nunca foi igual...}

No teu colo, nunca foi igual

À outra uma noite de alcova,

Teu corpo é uma lua de setembro

Sempre rica em fruta nova.

Os seios são cachos de uvas,

E dentro pulsa o vinho quente,

Os olhos são um portal no Céu,

Por onde entra meu desejo ardente.

Por ter procurado conservar as rimas alternadas (mesmo que substituindo as ricas do original por pobres na segunda estrofe), tive de sacrificar o metro - os chamados "vierfüßige Jamben" (jâmbicos de quatro pés ou versos de oito sílabas), pois, em função da reprodução do esquema de rimas, fui obrigado a alterar o ritmo do poema, conferindo um pulso mais livre aos versos na tradução. No segundo verso da segunda estrofe, em vez de "junger Wein", que seria "vinho jovem", optei por "vinho quente", em favor da rima com "ardente" que se mostrava oportuna e, apesar da alteração do sentido exato, correspondia à mensagem do verso de acordo com a minha leitura.

Passemos agora ao autor, libretista e produtor cinematográfico austríaco Felix Dörmann (de fato Felix Biedermann, 1870-1928), que obteve sucesso no início do século principalmente como contista, dramaturgo e poeta, bem como autor de libretos para óperas. Sua carreira como produtor de filmes, durante os primórdios do cinema na Áustria, foi breve e não atingiu o êxito almejado. Alguns de seus filmes foram censurados pela polícia por exibir cenas de nudez explícita das protagonistas no chuveiro, trocando de meias e 
até mesmo no toalete. Esses filmes são: Ein Tag im Leben einer schönen Frau ("Um dia na vida de uma bela mulher"), Die Göttin der Liebe ("A deusa do amor") e Seitensprung ("Escapadela"), todos de 1914. Naquele mesmo ano, a companhia de cinema fundada por Dörmann em 1912 encerrou suas atividades, também em virtude da constante falta de sucesso. Essas suas três produções cinematográficas contam hoje entre as primeiras do gênero erótico na Europa, mas, segundo me consta, não foram lançadas no Brasil.

Sua obra poética inclui as coletâneas: Neurotica (1891), Sensationen ("Sensações", 1892) e Gelächter ("Gargalhadas", 1896), também sem traduções conhecidas para o nosso português.

O poema a seguir está incluído na primeira delas, que parece encerrar em seu título um jogo de palavras entre o adjetivo "neurótica" e a ideia de um "novo erotismo" ("neue Erotica"):

\section{Schweigend}

Wir haben in seligen Nächten

Blutsaumige Küsse getauscht,

Wir haben in stöhnenden Wonnen

Die hungernden Seelen berauscht.

Wir liebten uns bis zur Erschöpfung

Und liebten auch dann uns noch fort,

Doch niemals entglitt unsren Lippen

Ein einziges zärtliches Wort. 


\section{Calados}

Trocamos, em noites felizes,

Centenas de beijos fervorosos,

Extasiamos nossas almas famintas

Em gemidos deliciosos.

Amamo-nos até o esgotamento,

E depois amamo-nos ainda mais,

De nossos lábios, porém, não escapou

Uma palavra terna jamais.

Da mesma maneira que na tradução do poema anterior de Dauthendey, procurei preservar aqui as rimas alternadas e não a metrificação (neste caso também definida por versos de oito sílabas), mesmo tendo sacrificado as rimas ricas da segunda estrofe por pobres, em favor da reprodução mais próxima e direta do sentido (como eu o interpreto). Apesar de ter aberto mão do metro em benefício da estrutura de rimas, esforcei-me em conservar a mensagem e a intensidade do poema, conforme a minha leitura, por meio da escolha de um léxico de impacto semântico que me pareceu equivalente.

E com isso chegamos ao último poeta apresentado aqui, um grande representante do expressionismo alemão: o poeta e dramaturgo August Stramm (1874-1915). O estilo de sua poesia, caracterizado pela brevidade, certa dureza e por experimentos linguísticos surpreendentes para a época, difere sensivelmente do da poesia expressionista de seus contemporâneos. Dos três poetas deste arti-

No site da Revista Zunái (http://www.revistazunai.com.br/traducoes/august_stramm.htm) estão disponíveis também seis poemas de Stramm traduzidos por Augusto de Campos, que pertencem à coletânea Tropfblut (algo como "Sangue gotejante"), volume de poemas de guerra publicado postumamente em 1919. 
go, é o mais conhecido no Brasil, tendo sido traduzido, entre outros, por Augusto $^{3}$ e Haroldo de Campos, que dedicou ao poeta alemão um ensaio em seu livro O arco-íris branco (Imago, 1997), no qual apresenta também traduções de alguns dos seus trabalhos.

Além de uns poucos poemas esparsos, Stramm publicou em vida apenas uma coletânea (1915), com o título Du. Liebesgedichte ("Tu. Poemas de amor"). A esta pertence o poema escolhido, bastante representativo do seu estilo:

\section{Spiel}

Deine Finger perlen

Und

Kollern Stoßen Necken Schmeicheln

Quälen Sinnen Schläfern Beben

Wogen um mich.

Die Kette reißt!

Dein Körper wächst empor!

Durch Lampenschimmer sinken deine Augen,

Und schlürfen mich

Und

Schlürfen schlürfen

Dämmern

Brausen!

Die Wände tauchen!

Raum!

Nur

Du! 


\section{Jogo}

Teus dedos rolam

E

Rodam Batem Brincam Adulam

Maçam Cismam Dormem Tremem

Ondeiam ao meu redor.

A corrente se rompe!

Teu corpo se alevanta!

Em meio à leve luz teus olhos baixam

E me sorvem

E

Sorvem sorvem

Anoitecem

Efervescem!

As paredes submergem!

Espaço!

Só

Tu!

Uma vez que o poema, por ser composto de versos brancos, não apresenta um esquema de rimas, a reprodução exata de sua estrutura não coloca nenhuma dificuldade específica para o tradutor. Se, por um lado, a limitação imposta por uma disposição de rimas não está presente, facilitando com isso a equivalência do léxico pela qual se pode reproduzir o sentido e a intensidade do poema, por outro lado a sua metrificação, de certa simetria descontínua, põe alguns problemas. Os versos três e quatro ("Kollern Stoßen Necken Schmeicheln/ Quälen Sinnen Schläfern Beben") possuem sete sílabas poéticas no original, compostas por verbos justapostos de duas sílabas no alemão, que, se traduzidos de maneira mais espontânea, 
se tornariam verbos de mais sílabas em português, aumentando assim de modo indesejado o comprimento do verso. Procurei aqui então encontrar no português verbos de significado equivalente e mesmo número de sílabas (com exceção de "Adulam"), de modo a "salvar" tanto o metro quanto a ideia do original: "Rodam Batem Brincam Adulam/ Maçam Cismam Dormem Tremem" (a perda do efeito de ambiguidade entre a terceira pessoa do plural e o infinitivo alcançado no original alemão pelo emprego das iniciais maiúsculas foi inevitável). O sexto e o décimo quarto versos ("Die Kette reißt!/ Die Wände tauchen!") possuem quatro sílabas poéticas cada, o que, tendo em vista a minha interpretação do conteúdo do poema, preferi reproduzir em seis: "A corrente se rompe!/As paredes submergem!". O que considerei de maior importância neste caso foi manter a simetria na métrica entre os dois versos distantes entre si. $\mathrm{O}$ verso de número oito ("Durch Lampenschimmer sinken deine Augen") é um perfeito pentâmetro jâmbico, que me esforcei por reproduzir na tradução, compondo um decassílabo equivalente em português: “Em meio à leve luz teus olhos baixam".

Os verbos "perlen" e "kollern" (versos um e três), apesar de significarem, respectivamente, "escorrer" e "gorgolejar", neste contexto parecem querer referir-se ao movimento de pérolas ou bolas de gude que rolam e/ou rodopiam, ao passo que "perlen" representa algo menor e mais fino, e "kollern", um movimento um pouco mais veemente.

As traduções apresentadas e comentadas aqui funcionam igualmente como uma tentativa de dar a conhecer o nome desses poetas e dramaturgos a leitores brasileiros que porventura não os conheçam, intenção de onde provêm os breves dados acerca de sua vida e obra incluídos aqui e que não se relacionam em todos os casos com a esfera erótica dos poemas. 